\title{
O Poeta e o Crítico, Diálogo Entre DRUMMOND E CANDIDO
}

\section{The poet and the critic, dialogue between Drummond and Candido}

\author{
Antônio Marcos V. Sanseverino*
}

\section{INTRODUÇÃO}

Em A poesia em 1930, Mário de Andrade (1974) escreve sobre a publicação dos livros de Carlos Drummond de Andrade, Alguma Poesia, Augusto Frederico Schmidt, Pássaro Cego, Murilo Mendes, Poemas, e Manuel Bandeira, Libertinagem. Bandeira, Drummond e Murilo, pelo menos, representam a consolidação da poesia moderna no Brasil, que busca o ritmo pessoal, não pela facilidade, mas pelo uso rigoroso do verso livre, visto como uma "vitória do individualismo" (1974, p. 28) Destaque-se, então, desde já que a poesia brasileira escrita nos anos 30 dialoga diretamente com o problema da modernização. Já na abertura da década, em 1930, são anunciadas diferentes respostas poéticas: o lirismo católico e versos discursivos de Augusto Frederico Schmidt; a consolidação do lirismo desentranhado do cotidiano em Bandeira; a tensão imagética de Murilo que se encaminha para a saída religiosa da poesia em Cristo; e, por fim, o diálogo e inquieto de Drummond que mergulha nos dilemas da modernidade à brasileira, pelo viés do lirismo irônico.

No presente artigo, a hipótese básica é de que as referências críticas de Antonio Candido, no tocante a poesia, formaram-se concretamente pela recepção desses poetas. Especificamente é a poesia moderna de Drummond que ajuda a formar o crítico enquanto leitor da lírica brasileira, em contraste ao lirismo de Manuel Bandeira.

Sul. 


\section{Anos 30}

Em entrevista concedida a Heloísa Pontes (2001), Antonio Candido descreve a importância de sua formação nos anos 30 e no início dos anos 40. Jovem, ele frequentou o Curso de Ciências Sociais, que então se construía com a participação de professores franceses. Acompanhou de perto a produção de Gilberto Freyre, de Sérgio Buarque de Holanda, de Caio Prado Jr. Leu os romances que iam sendo lançados nessa época - José Lins do Rego, Graciliano Ramos, Jorge Amado, Érico Veríssimo...

Essas informações dão a vocês uma idéia do que foi o meu curso de Ciências Sociais e Políticas, e serve para preveni-los contra a romantização do passado. Nós pertencemos a uma fase heróica da Faculdade, que foi a implantação dos cursos pelos professores estrangeiros. Era o começo daquele tipo de estudos, havia ainda muito diletantismo, nós transitávamos da arte para a filosofia, da sociologia para a literatura. Mas ao nosso lado havia rapazes e moças que já se orientavam pelas exigências da especialização (PONTES, 2001, p. 18).

Ao descrever os anos iniciais, mostra como a especialização não dominou por completo a formação de sua geração. Assim, os criadores da revista Clima transitavam entre sua área de raiz e outros interesses e, no caso dele, entre Sociologia e Literatura. Interessa agora destacar o modo como essa lembrança é construída: fase heroica, implantação, começo... A ênfase está posta no caráter inicial de um tipo de experiência acadêmica que não havia antes no Brasil. Nessa mesma entrevista, Candido declara que no período em questão respondeu a uma pergunta de Décio de Almeida Prado sobre que tipo de trabalho gostaria de produzir, disse preferir a produção de um ensaio a um romance (PONTES, 2001, p. 8).

Vejamos um trecho de Literatura e Cultura de 1900 a 1945:

Constatemos de inicio (como já tive oportunidade de fazer em outro escrito) que as melhores expressões do pensamento e da sensibilidade têm quase sempre assumido, no Brasil, forma literária. [...] Diferentemente do que sucede em outros países, a literatura tem sido aqui, mais do que a filosofia e as ciências humanas, o fenômeno central da vida do espírito (CANDIDO, 1985, p. 130).

Como se pode ver nesse texto, escrito nos anos 50 , encontramos a proposição de que a literatura (até o período de 30), mesmo na obra de um Euclides da Cunha, era uma forma de pensar o Brasil. Em um país em que 
não havia ainda especialização do trabalho intelectual, cabe à obra literária a tarefa de encenar a experiência brasileira em sua especificidade. Essa é uma marca do caráter empenhado da literatura, de tal modo que cabe aos escritores brasileiros, desde o romantismo, contribuir para a construção da literatura e da nação. Assim, como intelectual que procura estar à altura de seu tempo, Candido mostra que sua geração viveu o deslocamento da literatura para o ensaísmo. Essa passagem, localizada nos anos 30, faz com que tenhamos a convivência próxima de romancistas, poetas, ensaístas como intelectuais empenhados na tarefa de formar o Brasil. Cabe destacar no exemplo de Raízes do Brasil, que existe a consciência de que o processo formativo não está completo no Brasil, de que a compreensão do passado brasileiro leva o intelectual a projetar a mudança necessária. É nesse decênio que vai se formar uma pré-consciência do subdesenvolvimento, em que o pessimismo de Graciliano Ramos mostra o atraso brasileiro entranhado nas tensões de um Fabiano ou um Paulo Honório (CANDIDO, 1986).

A hipótese é de que as referências críticas de Antonio Candido formaram-se na convivência com a produção literária desse período, com a consolidação das premissas modernistas entre a sua geração de intelectuais. No caso específico do presente artigo, interessa focar agora o lugar dos poetas dos anos 30 nesse processo: Carlos Drummond de Andrade e Manuel Bandeira; Augusto Frederico Schmidt; Murilo Mendes e Jorge de Lima; Cecília Meireles e Henriqueta Lisboa...

A poesia moderna se consolida no Brasil seguindo uma condição ambivalente: o intelectual deve trabalhar para o Brasil; o lírico deve mergulhar em sua subjetividade liberta. De um lado, então, temos a imposição percebida por Candido de que cabe ao literato pensar o Brasil. Digamos que esse impulso vem desde os anos vinte. No início de sua correspondência com Drummond, Mário de Andrade, depois de dizer que alguns modernistas como os de Minas eram homens de gabinete, faz a seguinte conclamação:

Eu sofro com isso. Carlos, devote-se ao Brasil, junto comigo. Apesar de todo o ceticismo, apesar de todo o pessimismo e apesar de todo o século XIX, seja ingênuo, seja bobo, mas acredite que um sacrifício é lindo. O natural da mocidade é crer e os jovens não crêem. Que horror! [...] Nós temos que dar ao Brasil o que ele não tem e que por isso até agora não viveu, nós temos que dar uma alma ao Brasil e para isso todo sacrifício é grandioso, é sublime. E nos dá felicidade (SANTIAGO, 2002, p. 51, grifo nosso). 
A linguagem de Mário é de marca religiosa (devoção, crença, alma e sacrifício); a causa pela qual se deve lutar é o Brasil, para lhe dar uma alma. É radical a exigência de empenho, é extrema a imposição de que o escritor, como intelectual deve se dedicar a pensar o país. Ao mesmo tempo, é o mesmo Mário que vai dizer que o verso livre é uma vitória do individualismo. E esse é o outro lado da questão, o lirismo tradicional pressupunha o mergulho na interioridade, do sujeito que se volta sobre si mesmo, que se desliga do imperativo externo. No caso moderno, a tensão já é dada pela dimensão misturada entre o cotidiano e o poético, entre o baixo e o elevado, mas ganha uma dimensão maior quando ao poeta (escritor e intelectual) cabe ainda a tarefa de pensar um país.

Na carta em que responde a Mário, Drummond é duro e incisivo:

Reconheço alguns defeitos que aponta no meu espírito9. Não sou ainda suficientemente brasileiro. Mas, às vezes, me pergunto se vale a pena sê-lo. Pessoalmente, acho lastimável essa história de nascer entre paisagens incultas e sob céus pouco civilizados. [...] 0 meio em que vivo me é estranho: sou um exilado. [...] Desculpe se vou estender-lhe ante os olhos a velha tragédia de Joaquim Nabuco, um pouco deteriorados. [...] Detesto o Brasil como a um ambiente nocivo à expansão do meu espírito. [...] Enorme sacrifício; ainda bem que você o reconhece! Aí o lado trágico do caso. É um sacrifício a fio, desaprovado pela razão (como todo sacrifício). Confesso-lhe que não encontro no cérebro nenhum raciocínio em apoio à minha atitude. Só o coração me absolve. E isto não basta. Há sempre um caquinho de lógica procurando intrometer-se entre as nossas contradições. Daí as dúvidas, as flutuações do meu espírito... (SANTIAGO, 2002, p. 56-59, grifo nosso).

Os trechos recortados dessa fascinante resposta de Drummond ajudam a perceber o dilema a que se impõe um intelectual como o poeta mineiro. Ele volta um passo atrás em relação à crença de Mário, desconfia da necessidade do sacrifício a que se impõe e não encontra apoio racional que o justifique. Em 1924, seis anos antes do lançamento do primeiro livro, estamos aí frente ao dilema, à inquietação que Drummond levará para dentro de sua poesia. Bastaria lembrarmos o verso final de Hino Nacional, de Brejo das Almas (1934): "Nenhum Brasil existe. E acaso existirão Brasileiros?".

Salvo engano, então, no processo de modernização dos anos 20 e principalmente dos anos 30, as alterações da sociedade, o processo de urbanização, os dilemas históricos criam condições para expressão de uma lírica moderna. Em outros termos, a urbanização, imigração intensa, as lutas sociais e políticas e a modernização conservadora criam condições históricas em que irrompe a expressão poética moderna. 


\section{Plataforma de Uma GERAÇÃO ${ }^{1}$}

Em julho de 1943, Antonio Candido responde a um inquérito realizado por Mário Neme para $O$ Estado de $S$. Paulo, em que levanta a posição dos nomes que ganharam destaque no início dos anos 40.0 jovem crítico da revista Clima, com 25 anos, escreve logo no início que a síntese de sua posição está em um poeta, que veio da geração anterior. São os poemas de Carlos Drummond de Andrade, inclusive os inéditos de $A$ rosa do povo, que melhor expressariam o tempo de inquietude e de melancolia (2002, p. 238).

Mas Carlos Drummond de Andrade é uma exceção. A sua geração foi uma geração sacrificada... por excesso de êxito. A gente de 22, que é mais ou menos a dele, prestou um grande serviço ao Brasil, tornando possível a liberdade do escritor e do artista. [...] Poucos tiveram força para arrancar a sua obra ao experimentalismo hedonístico, e se perderam na piada, na virtuosidade e na ação política reacionária. [...]

Mas veio 30, e com ele, os filhos espirituais do pessoal de 20. A geração que se situa acima da nossa, e da qual nós dependemos de perto, $[\ldots]$

Para falar a verdade, com os de 30 é começa a literatura brasileira. Surgem os escritores que pouco devem ao modelo estrangeiro, os estudiosos que começam a sistematizar o estudo do Brasil e proceder á análise generalizada dos seus problemas (CANDIDO, 2002, p. 239-240, grifo nosso).

A citação é longa, os recortes suprimem passos da argumentação, mas vale destacar a força de Carlos Drummond de Andrade e a identificação do grupo de 1922 como geração heroica. O aspecto fundamental é a percepção de que a literatura brasileira começa em 30. Para o crítico, formado na escola de sociologia, não foi no arcadismo, nem romantismo, nem mesmo com Machado. É com os de 30 que a literatura brasileira se constitui. Em sua explicação, aparece um argumento de que se trata de uma geração que segue um processo interno, que leu e aproveita as conquistas de seus predecessores. Evidencia-se a semelhança (para não dizer dívida) para com a leitura que Mário de Andrade fazia do movimento modernista na famosa conferência de 1942, mas há algo mais. Temos aí o germe dos conceitos da Formação da Literatura Brasileira. 
Cabe considerar, então, que, estando ainda no começo, teríamos muito que fazer. Além disso, temos uma geração que se lança para o futuro, que se projeta a partir dos primeiros passos de uma trajetória. Se a consciência do atraso está se formando, se a literatura está pensando o Brasil a partir de suas mazelas, também é certo de que há um horizonte promissor possível. Nesse sentido, seria importante considerar como está se dando a circulação das obras literárias nesse período.

$\mathrm{Na}$ prosa, temos o fortalecimento do movimento editorial, do lançamento de novos romancistas e de uma descentralização da produção literária. Paradoxalmente, ou no mínimo contraditoriamente, a produção em prosa não é diretamente tributária da renovação de vanguarda. $O$ aspecto experimental é deixado de lado para se voltar a uma representação da realidade segundo os preceitos do realismo. Seja no romance voltado para temática urbana, seja no voltado para temática rural, os romancistas não seguem os modernistas paulistas. No máximo, estabelecem um diálogo tenso. Por exemplo, Graciliano, talvez a melhor prosa do período, se afasta intencionalmente da geração de 22 , e seu estilo não é uma consequência da libertação modernista. Ou poderíamos pensar em José Lins do Rego. Estamos aí lidando com alguém muito próximo de Gilberto Freyre, do movimento regionalista nordestino. Assim, um romance como Menino de Engenho, um memorialismo profundamente realista, se aproxima muito dos estudos sobre a família patriarcal.

O paradoxo se acentua quando vemos que a identificação de Candido no referido texto é mais forte com a poesia de Drummond. É o autor de referência. Aí entramos em um âmbito de consolidação da poesia modernista. Estamos lidando com a poesia moderna brasileira e aí, parece-nos, a limpeza modernista abriu espaço para uma produção poética sem a linguagem rebarbativa dos parnasianos. De certo modo, o modernismo paulista criou condições para que a poesia interiorizasse as tensões da modernidade, da efemeridade do cotidiano e da tentativa de ainda se encontrar o lirismo.

Para mostrar esse processo, basta estudar a trajetória de Manuel Bandeira. Por mais importante que sejam Cinza das Horas e Carnaval, esses livros não se comparam com a produção que vem depois de Ritmo dissoluto. O desrecalque do cotidiano - da linguagem e do tema - entra no lirismo de Bandeira, de tal modo que o mínimo e o escondido podem servir de mote para expressão do sujeito. Não há derramamento de lágrimas, não há excesso de emoção, não há afetação... O verso livre abre a poesia para o mundo prosaico; o lirismo se articula com a narração do mundo cotidiano; a alta revelação se mistura à matéria baixa da vida comum... Enfim, no largo espectro da poesia moderna, não há como pensar os de 30 sem a explosão modernista. 
Cabe destacar, contudo, no que tange a poesia, de que estamos tratando de um sistema precário. Os livros têm tiragens mínimas $(50,100$, 150 exemplares), custeadas pelos próprios autores e com circulação restrita. Em outros termos um dos pilares do sistema literário, a existência de público, é posta em xeque. Lendo a correspondência de Mário de Andrade com Bandeira ou com Drummond, vê-se a dificuldade de produção de um livro, a restrição das editoras para lançarem poesia. Não vende, não tem mercado. É o que leva Bandeira, em 1923, a chamar Monteiro Lobato de "canalha, cuja palavra não merece fé" (MORAES, 2000, p. 103). Havia prometido a publicação de Ritmo dissoluto, mas não o fez. Antes de prosseguir, não se pode esquecer que se trata do mesmo Lobato, responsável por editar um bom número de importantes prosadores.

Ao mesmo tempo, temos em 30 a consagração desses poetas intelectuais, como grandes escritores e como prestigiadas figuras públicas. Para dar um exemplo, podemos marcar a comemoração do cinquentenário de Manuel Bandeira e a seguir sua eleição para a Academia Brasileira de Letras. Nesse sentido, temos uma geração que leu os antecessores (dialogando com a tradição brasileira), estabilizou a forma poética moderna (sem esquecer sua diversidade), produziu obras que circularam e tinham forte impacto cultural, porém o público era restrito (quase um autopúblico), construído pelos próprios intelectuais.

Esse comentário é importante de ser feito, pois Antonio Candido trabalha e se forma como crítico a partir da leitura desses poetas brasileiros dos anos 30. Talvez seja possível identificar como modelos, que constantemente são citados e retomados, Manuel Bandeira e Carlos Drummond de Andrade. Tão diferentes entre si, mas encarnação da poesia moderna em duas facetas distintas, no primeiro uma tendência à acomodação e no segundo uma tensão que leva a uma constante desconfiança e inquietude de seu lirismo.

Por esse aspecto de $A$ plataforma de uma geração, chegamos à problemática distinção de Bandeira como poeta menor e de Drummond como nosso grande poeta social. Antes de avançarmos, cabe citar outro texto de Candido:

Se observarmos a poesia brasileira, veremos que ela é formada por uma maioria de poetas menores - isto é, poetas de emoção não organizada e dirigida, que se contentam com a pincelada, o toque, a sugestão rápida, o momento de beleza. Não há quase poetas maiores - isto é, aqueles que fazem do verso um instrumento de totalização da experiência humana, dirigindo-se tanto á inteligência quanto à sensibilidade ou ao gosto. O Sr. Manuel Bandeira é tipicamente um poeta menor (CANDIDO, 2002, p. 130). 
O trecho acima, parte de "Notas de Crítica Literária - sobre poesia", foi escrito em abril de 1944, um ano após o outro texto. Aí vemos claramente a definição de que a tendência da poesia brasileira é ser menor, apegada à expressão fugaz da emoção, a captação do momento de beleza. Mais adiante, Candido diz, tendo Bandeira como exemplo de poeta menor:

o que não há dúvida é que a supremacia do poema curto, centralizado em torno de uma simples emoção ou consistindo num jogo poético de habilidade, significa diminuição do tônus da poesia, um divórcio do poeta com o mundo, a sociedade, para confiná-lo a uma certa passividade ou a um certo enrolamento sobre ele próprio (CANDIDO, 2002, p. 132).

Ao comentar, então, a poesia menor, tendo Bandeira como exemplo, Candido estabelece um juízo de valor desfavorável. O poeta volta-se para dimensão individualista, de mergulhar em si, de captar o momento poético no mundo. O critico esperava em 1944, em tempo de guerra no mundo e de ditadura no Brasil, o outro polo um casamento com o mundo e com a sociedade, talvez seja possível de se dizer que o crítico esperava um certo sentimento do mundo, como aparece em um poeta maior como Drummond.

Retomando o fio posto pela Plataforma de uma geração, Candido define para Mário Neme que o grande problema de sua geração é o medo, e a grande tarefa que se impõe é "o combate a todas as formas de pensamento autoritário" (CANDIDO, 2002, p. 245). Candido elege o poeta mineiro como intelectual modelo para sua geração. Na contraposição entre os dois textos e, mais, entre os dois poetas, fica clara a opção do crítico.

Não custa retomar que a atitude crítica e vigilante compreende a necessidade de analisar o próprio tempo através do estudo sistemático e do lento amadurecimento. Assim, o dever é combater todas as formas de reação: filosofia idealista (ontologias); o culturalismo (Gilberto Freyre) e a literatura personalista (autocentramento). Nesse sentido, ao se impor a necessidade de enfrentar o medo, Candido refere-se implicitamente ao Estado Novo e também a todas as formas reacionárias que dominam o cenário intelectual brasileiro.

Ao publicar $A$ rosa do povo, em 1945, Drummond isola um pequeno trecho do referido artigo como epígrafe do poema $O$ medo: "Porque há para todos nós um problema sério... Este problema é o medo". Além do caráter circular do crítico que lê o poeta, que cita o poeta, cabe apontar a escolha do trecho mais amplo e mais genérico da citação, que evita a continuação, o medo de não estar à altura da tarefa de seu tempo. Independente disso, o poeta mineiro é exaltado por sua dimensão pública, por sua força crítica. 
Em Manuel Bandeira, então, encontramos o poeta que se declara, não sem ironia, um poeta menor, que vai desentranhar a poesia que está presente no cotidiano. Na sua fase madura, a partir de Ritmo Dissoluto (1924) e depois em Libertinagem (1930), Manuel Bandeira despe-se da retórica simbolista e se apega à realidade, para revelar a dimensão poética em uma forma nova. Essa outra dicção poética que não tem nem a ambição, nem a força da poesia do alto voo Drummondiano.

Aqui poderíamos considerar um poema de Sentimento do mundo, mãos dadas. Temos aí a necessidade de se voltar para o tempo presente, para a intervenção no tempo histórico. Cabe opor a Murilo de tempo e eternidade. Além disso, não se trata da lírica de Cecília, cuja resposta dada ao problema da modernidade é a de se voltar para o lirismo puro, para uma forma que se afasta dos problemas históricos ou vai transcendê-los. Talvez seja o momento de levantar as seguintes questões:

\section{Inquietudes de Um PoetA}

Segundo Candido, o núcleo da obra de Drummond se define pela presença de uma "subjetividade tirânica" (CANDIDO, 1995, p. 113), que se impõe, mas o deixa culpado, contrafeito. Isso gera uma inquietude "que o faz oscilar entre o eu, o mundo e a arte, sempre descontente e contrafeito" (CANDIDO, 1995, p. 113). Esse funcionamento da poesia de Drummond depois é desdobrado na análise da forma como o eu "todo enrodilhado" se apresenta, como o mundo caduco impõe-se pelo terror e pelo medo, como o poeta da família se forma herdeiro e desvio do padrão patriarcal e, por fim, como a concepção de poesia amadurece ao longo de sua obra. Para o presente artigo, interessa observar alguns aspectos da leitura de Candido.

Em primeiro lugar, o crítico encontra o fundamento da obra de Drummond, seu princípio fundante. De Alguma poesia até Lição de Coisas, temos uma unidade centrada na inquietude, na oscilação do eu e o mundo, eu e a família, eu e a poesia, tudo com o constrangimento de quem não se sente à vontade.

É a convivência necessária, interligada e desigual entre os dois termos. Drummond não confia nem na sua subjetividade, nem no mundo. Não exalta a família patriarcal, mas não a substitui pela perspectiva moderna. Desconfia da modernidade, apegado aos resíduos e restos deixados pela cidade, mas não há saída, nem encontra consolo na lembrança de uma Pasárgada itabirana. Nessa fissura entre os termos, nesse instante que se coloca entre um e outro, que a poesia de Drummond se instala e interessa ao crítico, tanto que não lhe interessa o momento de estabilização quando 
Drummond "não põe em dúvida a integridade do seu ser, a sua ligação com o mundo, a legitimidade da sua criação" (CANDIDO, 1995, p. 111).

Na releitura do texto de Candido, seguindo as pistas lançadas e as articulando com outros artigos, talvez seja possível dar mais um passo. Talvez se possa dizer que esse "núcleo emocional que organiza a experiência poética" (CANDIDO, 1995, p. 115) seja tanto de Drummond quanto da realidade brasileira.

Para pensar a força da lírica de Drummond, talvez seja interessante de se ponderar uma posição anterior, dos anos 20, a de Oswald de Andrade e sua poética pau-brasil e depois antropofágica. Segundo Roberto Schwarz (1988, p. 11) Oswald inventou "uma fórmula fácil e eficaz de ver o Brasil". A matéria prima está posta na justaposição entre traços próprios do Brasil colônia e do Brasil burguês. A realidade cotidiana serve de fundamento para essa forma que acaba por construir uma alegoria do Brasil (SCHWARZ, 1988, p. 12), mas há aí uma feição otimista para o tema, uma prefiguração de uma humanidade pós-burguesa e fraterna. Assim, em Pobre alimária, Oswald constrói a integração entre autoridade tradicional e modernidade (SCHWARZ, 1988, p. 17). Essa duplicidade penetra a forma do poema, em que se mistura os traços típicos da vanguarda (substantivos crus, ausência de musicalidade do verso, negação da sentimentalidade subjetiva, feição rudimentar, distância do objeto...) e a força da tradição liberta de hierarquias. Em outros termos, o poema superpõe coordenadas incongruentes.

Esta distância que permite passar por alto os antagonismos e envolver as partes contrárias numa mesma simpatia naturalmente é um ponto de vista". Nesse movimento há a suspensão do conflito, do antagonismo entre as matérias colonial e burguesa (atrasada), "bem como descaso pelos conteúdos subjetivos" (SCHWARZ, 1988, p. 21).

Desse modo a contradição nuclear de Oswald de Andrade está em trabalhar o lirismo em uma forma moderna e de feição crítica (modelo de desidentificação brechtiano), mas procurar ao mesmo tempo a informalidade de um país não proprietário, assim como a conciliação, perspectiva ideológica. A feição moderna está, por exemplo, em Canto de Regresso à pátria, no desvio do primeiro verso (Minha terra tem palmares), mas ao mesmo tempo introduz o mito edênico de Gonçalves Dias no núcleo histórico da revolta de escravos. Assim, Oswald está constantemente procurando o lugar da conciliação, em que se atenuam os antagonismos, se aparam as arestas e se pode projetar o matriarcado de pindorama.

Ao voltar ao Drummond valorizado por Candido, o poeta das inquietudes, vemos o forte contraste que há em relação a Oswald. A tensão 
entre arcaico e moderno também está presente, mas não se procura um lugar de conciliação, pois não há mais. Ao negativo da tradição patriarcal, corresponde ironicamente a modernização dos anos 30. Drummond tem como matéria poética o tempo presente, enquanto choque de tempos, tentando inserir-se no movimento da história. o ponto nevrálgico, sofrido e trágico em Drummond, é que ele se situa em um impasse que não se resolve. Ironicamente consciente de que nenhum sacrifício vale a pena, ele se afasta do mundo patriarcal, mas não vê se afirmar o mundo moderno.

\section{AMARRANDo Alguns Fios}

Para efetuar o contraste entre a poesia de 30 e a obra de Drummond, valeria ainda estudar o conjunto de textos críticos produzidos por Antonio Candido. Sua produção crítica abarca desde a poesia de Cláudio Manuel da Costa, Álvares de Azevedo, Castro Alves, Alberto de Oliveira até a poesia de João Cabral de Melo Neto, sem esquecer o referido Estudo analítico do poema, em que as notas de aula revelam a fundamentação cuidadosa para o estudo da poesia.

Talvez seja possível se dizer que o interesse do critico, na leitura dos poetas brasileiros, desponta quando a forma poética é precipitação de tensões históricas, cifra da experiência brasileira, da oposição entre dois termos (entre local e cosmopolita, Brasil e Europa, particular e universal, Ariel e Caliban). Os pressupostos da leitura da poesia diferem da figuração de conjunto que se desenvolve em romances como Memórias de um sargento de Milícias ou em Cortiço. Nessas obras, Candido descobriu na forma do romance (aparentemente descontínua e dispersa) um princípio unificador que, com o perdão da simplificação, vinha da matéria histórica brasileira a dialética entre ordem e desordem ou o princípio de acumulação primitiva em nossa dialética cabocla.

No caso da poesia, Antonio Candido fez a abordagem por diferentes caminhos. Na sala de aula, livro de feição didática, o crítico faz análises de poemas (de Caramuru até Murilo Mendes). Nesse caso, interessa analisar o poema que integra em sua forma íntima às tensões da experiência humana, vai da análise do verso até chegar ao fundamento histórico. Nos textos da Formação da literatura brasileira, o estudo dos poetas árcades e românticos está inserido em um quadro histórico maior, parte da dialética entre localismo e cosmopolitismo e do processo de formação do sistema literário brasileiro. E, para o que aqui nos interessa, há aqueles estudos dedicados à obra de um poeta, como o estudo da obra de Drummond ou aquele que introduz a obra de Bandeira. 
Em todo caso, podemos dizer que, especialmente na lírica de Drummond, Candido analisa o embate do indivíduo que luta para encontrar a expressão, a forma capaz de traduzir sua subjetividade, mas ao mesmo tempo desconfia da validade de suas vivências pessoais. Se retomarmos a carta de Drummond a Mário de Andrade, antes citada, podemos pensar como seria a forma poética adequada para expressar o dilema de Nabuco em que o sentimento é brasileiro, mas a imaginação é europeia. Podemos pensar a ambição civilizada de um brasileiro que repudia a natureza de sua terra e a vergonha com o cotidiano rebaixado. Pressupondo a lírica, como expressão de subjetividade autônoma ou como mergulho interior, o dilema trágico de Nabuco tende a imobilizar o indivíduo que não se vê como sujeito, preso na paisagem tropical e sentido-se à vontade na cultura europeia (como Drummond a Mário).

Assim, Drummond é ponto máximo da realização nacional no âmbito da lírica moderna (talvez seja um caso excepcional?). Como autor, Drummond não apenas bebeu na tradição local (não seria possível Drummond sem Mário ou Bandeira), como também estudou sistematicamente poetas anteriores desde o romantismo. Sem esquecer que internalizou as formas da poesia ocidental, como, por exemplo, Baudelaire e Valèry. Gradualmente, como já se vê em Alguma Poesia, enraizou-se na particularidade (no desrecalque da matéria cotidiana), não perdeu o horizonte contemporâneo e acumulou larga experiência subjetiva que traduziu em poesia. $O$ resultado não é a contemplação serena do mundo, mas o movimento inquieto e irônico que sempre desconfia de si mesmo e do mundo. No núcleo de sua poética, sem deixar de considerar seu amadurecimento de Alguma Poesia a Lição de Coisas, temos a tensão, o confronto e às vezes ambivalência do indivíduo que se sabe ao mesmo tempo moderno e brasileiro.

Há o paradoxo forte, então, de que a literatura brasileira "começa em 30", pois traz um sistema poético formado e qualificado, ainda que rarefeito, que traduz as diversas experiências de uma geração, o embate de indivíduos que não completam a formação da subjetividade que luta entre imaginação postiça (europeia, de dicção artificial, de referências universais) e a experiência cotidiana (brasileira, de dicção coloquial, posta ao rés do chão, recalcada). Essa tensão ganha forma nova a partir do modernismo e atinge, ao que parece, sua força máxima em Carlos Drummond de Andrade.

Cabe ainda uma vez mais retomar a trajetória poética de Manuel Bandeira que mergulha, a partir de Ritmo Dissoluto (1924), no detalhe particular do cotidiano brasileiro para desentranhar a experiência poética. No desrecalque do cotidiano brasileiro, a fala, o gesto, a vivência e os ambientes prosaicos são mesclados à tradição lírica. A ruptura representou não apenas negação da tradição, como também abertura à experiência 
brasileira, como se pode dizer da incorporação de marcas e ritmos próprios da fala à escrita poética. A passagem de Cinza das Horas para Ritmo Dissoluto é exemplar dessa trajetória da poesia brasileira. Em Carnaval (1919), o poema Alumbramento evidencia o uso do ritmo convencional, com um tom crepuscular e imagens de tradição simbolista. Para mostrar o encantamento com a nudez feminina, o eu poético deve sublimá-la (eu vi os céus!) e purificá-la na tonalidade branca que perpassa o poema. Em Ritmo dissoluto (1924), o eu poético de Meninos carvoeiros fica escondido na posição de observador. Em tom coloquial, o poema ganha forma narrativa, mostrando os meninos que levam em sacos de aniagem o carregamento de carvão e depois voltam brincando no final do dia. Intercalado na narração aparece ainda um terceiro tempo, um velho que na boca da noite recolhe os restos de carvão caídos. A dimensão lírica aparece no modo como a descrição dos meninos, carvoerinhos, e no olhar espantado que vê as crianças trabalhando como se brincassem. O poeta, com o senso do momento poético, revela a dimensão lírica da realidade. A tensão aparentemente se desfaz, mas está lá dentro, na forma moderna que traz em primeiro plano, o olhar emocionado lançado sobre a cena rural.

Em um poema como Vou-me embora pra Pasárgada, que é um poema que surge em circunstância de "desalento e tédio", um "desabafo de evasão da vida besta" (BANDEIRA, 1996, p. 80). O impulso leva a escrever o poema como expressão pessoal e afetiva. Escrito em redondilha maior, na volta do metro popular da canção, o reino ideal e desejado traz todas as marcas desejadas na sua condição pessoal, o resgate da infância saudável e de suas brincadeiras. Há também as marcas da sexualidade realizada. Esse mundo, regrado pelo regime da satisfação do desejo, também traz os traços típicos da sociedade patriarcal e rural, que aparece em tom amenizado pela nostalgia. Como diz Bandeira, lá sou amigo do Rei, com o poder que os favores reais lhe abre, o eu poético tem as mulheres que quer em sua cama, namora prostitutas bonitas... Enfim, no embalo e na leveza da canção, no afastamento da vida besta, vem a diluição dos conflitos brasileiros.

Noutro plano da lírica dos anos 30, surge Viagem em 1938. Cecília Meirelles expressa a particularidade poética de tal modo que a imagem ganha uma dimensão lírica que não passa pela referência ao cotidiano, nem pela mediação brasileira. A imagem da natureza (o mar, a noite ou apenas uma gota de orvalho) tem o valor simbólico capaz de expressar uma dimensão interior do sujeito. A força do poeta não passa pelo diálogo com a tradição local ou pelo desrecalque da matéria brasileira. Esse exemplo é importante para se ver que a captação do poético na modernidade pode redundar na busca de um lirismo puro, ou depurado da contingência histórica. 
Voltando a Drummond, a subjetividade do poeta se constitui na relação tensa entre termos antagônicos e excludentes, que, no entanto, convivem obrigatoriamente mergulhados no tempo presente, que passa acelerado na cidade moderna. No mesmo indivíduo estão simultaneamente o arcaico e o moderno, o rural e o urbano, a família tradicional e o indivíduo moderno ou a vivência prosaica do cotidiano brasileiro e a dimensão cosmopolita ou universal. Alguma Poesia, Brejo das Almas (publicados ainda em Minas), Sentimento do mundo, José e depois Rosa do Povo mostram a trajetória de um poeta que traz o diálogo com as exigências dos anos 30 (como a necessidade de engajamento), com a modernidade dos grandes centros urbanos e com a permanência de uma sociedade tradicional. Assim, ele traz a ambição da expressão lírica, sem deixar de lado o tempo presente e a vida presente. Observe-se, então, que não há sublimação como em Cecília, nem a nostalgia de Bandeira. Os impasses da modernização conservadora se entranham como pedra na alma do poeta itabirano e como doem...

Nos anos 30, então, seguindo a pista de Candido, a literatura brasileira se forma como um sistema ativo e forte e, no caso específico da poesia, temos a constituição da moderna lírica brasileira, em suas diferentes vozes, como Bandeira e Drummond. Não são manifestações isoladas, mas poetas que se articulam através da publicação de suas obras e da leitura de seus pares. É um sistema precário, considerando o número de exemplares publicados de cada obra, mas é um sistema constituído que tomou o bastão dos debates poéticos da poesia dos anos 20. Após a explosão modernista, houve a procura de uma nova forma poética, que não estava dada pela tradição, nem poderia ser importada da Europa. Murilo volta-se para a poesia em Cristo, Cecília sublima a expressão subjetiva na pureza lírica, Bandeira parece o homem cordial que alia a forma moderna do poema à nostalgia da infância patriarcal, e Drummond encarna a tensão brasileira e a eleva a princípio de composição lírica, na busca de uma forma.

\section{RESUMO}

O presente artigo estuda a leitura da obra de Carlos Drummond de Andrade, realizada por Antonio Candido. O poeta mineiro é visto como figura exemplar da poesia brasileira que se constitui nos anos 30, enquanto sistema literário. Drummond também serve de modelo e referência da formação do crítico paulista enquanto leitor de poesia.

Palavras-chave: Antonio Candido; Carlos Drummond de Andrade; poesia brasileira. 


\begin{abstract}
This essay studies the way Antonio Candido reads Carlos Drummond de Andrade's writings. The poetry is seen as typical of the Brazilian poetry that grows in the thirties as a literary system. Drummond is also a model and an example for Candido, poetry reader.

Key-words: Antonio Candido; Carlos Drummond de Andrade; Brazilian poetry.
\end{abstract}

\title{
REFERÊNCIAS
}

ADORNO, Theodor. Notas de Literatura I. São Paulo: Duas Cidades; Editora 34, 2003. (Espírito Crítico).

ANDRADE, Mário de. A poesia em 1930. In: . Aspectos da literatura brasileira. 5. ed. São Paulo: Martins, 1974.

ARANTES, Paulo. Sentimento da dialética. São Paulo: Paz e Terra, 1992.

BANDEIRA, Manuel. Poesia completa e prosa. 4. ed. Rio de Janeiro: Nova Aguilar, 1996. CANDIDO, Antonio. A educação pela noite e outros ensaios. São Paulo: Ática, 1987. . Educação pela noite e outros ensaios. São Paulo: Ática, 1986.

Formação da literatura brasileira. 5. ed. Belo Horizonte: Itatiaia; São Paulo: Editora da Universidade de São Paulo, 1975. 1997. Iniciação à literatura brasileira (Resumo para principiantes). São Paulo: Humanitas, . Literatura e sociedade: estudos de teoria e história literária. 7. ed. São Paulo: Nacional, 1985. . O romantismo no Brasil. São Paulo: Humanitas, 2002. . Recortes. São Paulo: Companhia das Letras, 1993. - Tese e antítese. São Paulo: Nacional, 1964. . Textos de intervenção. São Paulo: 34; Duas Cidades, 2002. . Vários escritos. 2. ed. São Paulo: Duas Cidades, 1995.

JACKSON, Luiz Carlos. A tradição esquecida: Os parceiros do Rio Bonito e a sociologia de Antonio Candido. Belo Horizonte: Ed. da UFMG; São Paulo: FAPESP, 2002.

MORAES, Marco Antônio. (Org.). Correspondência Mario de Andrade e Manuel Bandeira. São Paulo: Edusp, 2000.

PONTES, Heloísa. Entrevista com Antonio Candido. Revista Brasileira de Ciências Sociais, São Paulo, v. 15, n. 47, out. 2001. 
SAnseverino, A. M. V. O Poeta e o Crítico, Diálogo entre Drummond e Candido

SANTIAGO, Silviano. (Org.). Carlos e Mário: Correspondência de Carlos Drummond de Andrade e Mário de Andrade. Rio de Janeiro: Bem te vi, 2002.

SCHWARZ, Roberto. Seqüências brasileiras. São Paulo: Companhia das Letras, 1999. . O bonde, a carroça e o poeta modernista. In: Companhia das Letras, 1988. . Que horas são? São Paulo:

Submetido em: 20/03/2008.

Aceito em: 25/11/2008. 